\title{
Atmospheric remote sensing using global navigation satellite systems: From FORMOSAT-3/COSMIC to FORMOSAT-7/COSMIC-2
}

\author{
Chung-Huei Chu ${ }^{1, *}$, Cheng-Yung Huang ${ }^{1}$, Chen-Joe Fong ${ }^{1}$, Shu-Ya Chen ${ }^{2}$, Yi-Hsiu Chen ${ }^{3}$, \\ Wen-Hao Yeh $^{1}$, and Ying-Hwa Kuo ${ }^{4}$ \\ ${ }^{1}$ National Space Organization, Hsinchu City, Taiwan \\ ${ }^{2}$ National Central University, Taoyuan City, Taiwan \\ ${ }^{3}$ Central Weather Bureau, Taipei City, Taiwan \\ ${ }^{4}$ University Corporation for Atmospheric Research Boulder, Colorado, USA
}

\begin{abstract}
Article history:
Received 26 May 2021

Revised 3 September 2021

Accepted 15 November 2021

Keywords:

Meteorology Satellite, FORMOSAT-3/COSMIC, FORMOSAT-7/COSMIC-2, Global Positioning System (GPS), Global Navigation Satellite System (GNSS), Radio Occultation (RO)

Citation:

Chu, C.-H., C.-Y. Huang, C.-J. Fong, S.-Y. Chen, Y.-H. Chen, W.-H. Yeh, and Y.-H. Kuo, 2021: Atmospheric remote sensing using global navigation satellite systems: From FORMOSAT-3/COSMIC to FORMOSAT-7/COSMIC-2. Terr. Atmos. Ocean. Sci., 32, 1001-1013, doi: 10.3319/TAO.2021.11.15.02
\end{abstract}

\begin{abstract}
The world's first Global Positioning System Radio Occultation (GPS-RO) constellation, the joint Taiwan-U.S. Formosa Satellite No. 3 - Constellation Observing System for Meteorology, Ionosphere \& Climate (FORMOSAT-3/COSMIC) has demonstrated the value of GPS-RO data in terrestrial weather, space weather, and climate study. The RO measurement technique was dubbed as "the most accurate and stable thermometer in space" because of its high accuracy, high vertical resolution, and high stability, which does not require calibration. Since its launch in 2006, FORMOSAT-3/COSMIC has accumulated over 6.9 million atmospheric and 4.6 million ionospheric RO sounding profiles. Encouraged by the success of FORMOSAT-3/ COSMIC, Taiwan's National Space Organization (NSPO, https://www.nspo.narl. org.tw/index.php? $\ln =e n)$ and the U.S. National Oceanic and Atmospheric Administration (NOAA) started the planning for the FORMOSAT-7/COSMIC-2 mission in 2008 as a follow-on program to FORMOSAT-3/COSMIC. The FORMOSAT-7/ COSMIC-2 satellite constellation, consisting of six small satellites, was successfully launched in June 2019 as the world's first operational RO satellite constellation focusing over the tropics. After fourteen years in service, providing valuable data to operational and research communities, FORMOSAT-3/COSMIC was officially decommissioned ten months after FORMOSAT-7/COSMIC-2 has been sent to space, and replaced by the FORMOSAT-7/COSMIC-2. As expected, the first results from FORMOSAT-7/COSMIC-2 showed positive impact on operational weather prediction and has observed interesting phenomenon in the ionosphere. In this paper, we will summarize the progress from FORMOSAT-7/COSMIC-2 up to date.
\end{abstract}

\section{INTRODUCTION}

Located at the heart of the "Typhoon Alley", Taiwan is hit by typhoons three to four times a year in average. The deadliest typhoon impacting Taiwan on record is Typhoon Morakot (2009) which killed about 700 residents and brought catastrophic damages causing a total loss over $\$ 3.3$ billion USD. Heavy rainfall and flash flooding brought by typhoons and Mei-Yu (or plum rain) fronts account for $89 \%$ of natural disasters in Taiwan. In 2019, there were 14 weather and climate events across the United States, with losses

\footnotetext{
* Corresponding author

E-mail:vicky@narlabs.org.tw
}

exceeding 1 billion US dollars per each event (NOAA NCEI $2020 \mathrm{a}, \mathrm{b})$. There is no doubt that improving our ability to predict severe weather is critical for disaster reduction.

The strength of constellation observation is on its capability of measuring massive data with similar satellite configuration. FORMOSAT-3/COSMIC and FORMOSAT-7/ COSMIC-2 deploy constellations of satellites to measure the signal's bending angle from Global Navigation Satellite System (GNSS), which is constellation system, too. As GNSS signal transmits through atmosphere and ionosphere, the path is bent because of the characteristics of the media. This phenomenon is also known as Radio Occultation 
(RO). The RO measurement technique was recognized as "the most accurate and stable thermometer in space" by the international atmospheric science communities owing to its high accuracy, high vertical resolution and high stability (Digregorio 2006; Chu et al. 2007; Liou et al. 2007). The bending angle measured by FORMOSAT-3/COSMIC and FORMOSAT-7/COSMIC-2 constellation is used to derive thousands of profiles of temperature, humidity, and pressure of atmosphere and the electron density of ionosphere every day.

The application of massive RO data includes improving terrestrial weather and space weather forecast, exploring the possibility of earthquake, and trying to make tsunami prediction, the National Space Organization (NSPO), Taiwan and the National Oceanic and Atmospheric Administration (NOAA), USA teamed up to develop a cuttingedge constellation known as FORMOSAT-7 (Formosa Satellite Mission \#7), also known as constellation observing system for meteorology, ionosphere, and climate \#2, or COSMIC-2 in the USA (Pica 2016). FORMOSAT-7/ COSMIC-2, consisting of six small satellites, is a followon program of FORMOSAT-3/COSMIC and was launched to space on 25 June 2019 (Fig. 1). After serving the international atmospheric science community for over fourteen years, FORMOSAT-3/COSMIC was officially decommissioned on 1 May 2020 and replaced by FORMOSAT-7/ COSMIC-2.

FORMOSAT-7/COSMIC-2 constellation, like its predecessor, is designed to collect atmospheric bending angles and refractivity profiles with improved data quality and quantity. The neutral atmospheric data have been made available to atmospheric science community since March 2020 through U.S. UCAR COSMIC website and Taiwan Analysis Center for COSMIC (TACC) website (CDAAC Website, https://cdaac-www.cosmic.ucar.edu/; TACC Website, https://tacc.cwb.gov.tw/v2/en/index.html), respectively. The data have been also accessible through the Global Telecommunication System (GTS) to support operational weather prediction since March 2020 (Weiss 2019, 2020; Schreiner et al. 2020). Following FORMOSAT-3/ COSMIC, FORMOSAT-7/COSMIC-2 adapts a free and open data policy to provide global data users with the near real time and the achieved RO data for operational weather prediction, climate, ionosphere, geoscience research, and non-commercial applications.

\section{HIGHLIGHTS OF FORMOSAT-3/COSMIC}

The key contributions of the FORMOSAT-3/COSMIC mission depicted in (Anthes et al. 2008; Yen and Fong 2009; Anthes 2011; IPCC 2013; Wang 2017; Ho et al. 2020) are highlighted as follows.

\subsection{Radio Occultation Data is Important Sources for Terrestrial and Space Weather}

The collected FORMOSAT-3/COSMIC atmospheric occultation count per day from 2006 to 2020 is plotted in Fig. 2. FORMOSAT-3/COSMIC has accumulated over 6.9 million atmospheric and 4.6 million ionospheric RO data profiles globally. It is noted that the count increased in 2012 because NSPO's system engineering team found an adaptive analysis method to perform the trend analysis on satellite telemetry, and used the results to predict the aging trend of onboard battery and then to optimize the battery operations and configuration. FORMOSAT-3/COSMIC is the world's most important source of ionospheric RO data, as it accounts for $90 \%$ of the collected 5 million ionosphere RO data profiles. Taiwan's space weather community has achieved a number of breakthroughs using the RO profile data.

GPS-RO ranked \#3 among other NOAA instruments in terms of impact per observation based on the Forecast Sensitivity to Observations (FSO) for 24-h forecast of wind, temperature and surface pressure. The RO bending angle data from FORMOSAT-3/COSMIC and METOP is ranked \#5 among all observing systems in reducing 24-h forecast error based on a study conducted by European Centre for Medium-Range Weather Forecasts (ECMWF). The 2017 report of World Meteorology Organization (WMO) International Radio Occultation Working Group confirmed positive impact of the GNSS-RO data on the global Numerical Weather Prediction (NWP). In which, future deployment of an operational constellation of GNSS-RO satellites capable of providing higher quality soundings with global coverage was highly recommended. The meeting of the Coordination Group for Meteorological Satellite emphasized the importance of RO data for global observation (Kurino 2016; Mannucci et al. 2018; Schreiner 2020). These endorse the conclusion for the need of a succeeding operational GNSSRO constellation observing system.

\subsection{The RO Retrieval Technique Enabled the Measurement of Atmospheric Boundary Layer Height}

FORMOSAT-3/COSMIC is the pioneer mission of meteorological satellite constellation for identifying the atmospheric boundary layer (ABL) from space in a novel approach. It is the world's first GPS-RO mission utilizing an open-loop tracking technique developed by UCAR (Sokolovskiy 2004), which allows more than $90 \%$ of the GPS-RO soundings to penetrate through the bottom of one $\mathrm{km}$ at high latitudes. The GPS-RO soundings were used to provide global measurements of ABL heights and seasonal/ geographical variations (Chien et al. 2016, 2019; Guo et al. 2011), which are important for scientists to perceive 
contributions of the data to tropical weather prediction and climate changes.

\subsection{Assimilation of RO Data into NWP System Showed the Improvement on Weather Forecast}

FORMOSAT-3/COSMIC's primary goal to demonstrate quasi-operational GPS-RO limb sounding for use in NWP was reached successfully within the first year after the data released to the global users. The ECMWF assimilated the RO profiles into its forecast system 8 months after its launch in 2006. It showed that the data can effectively reduce the temperature bias. Subsequently, the National
Centers for Environmental Prediction of U.S., the Meteorology Office of the United Kingdom, Meteo France, and Central Weather Bureau (CWB) of Taiwan also assimilated FORMOSAT-3/COSMIC data for operational weather prediction. All operational centers reported significant impact. It was reported that even though the FORMOSAT-3/COSMIC RO data accounted for $2-3 \%$ of the total data in 2012, it contributed to a $10 \%$ reduction in 24 -h forecast errors (Cardinali and Healy 2014; Lien et al. 2021).

There were several weather forecast experiments conducted on the typhoon season for a period of three days in Taiwan in 2008 showed that the inclusion of RO data has improved accuracy of typhoon track forecast Moreover, the

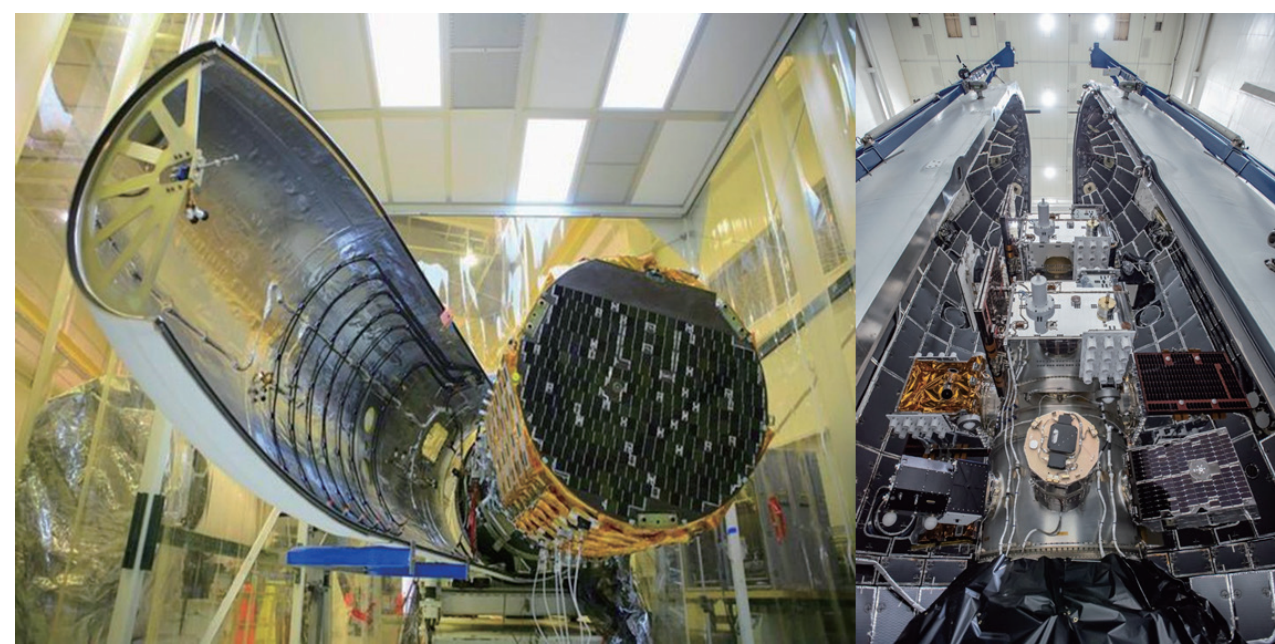

Fig. 1. Encapsulated FORMOSAT-3/COSMIC and FORMOSAT-7/COSMIC-2 Satellites. FORMOSAT-3/COSMIC six satellites were delivered to their injection orbit through Minotaur dedicated launch (left). FORMOSAT-7/COSMIC-2 six satellites were sent to their injection orbit through a shared ride of Falcon Heavy (right).

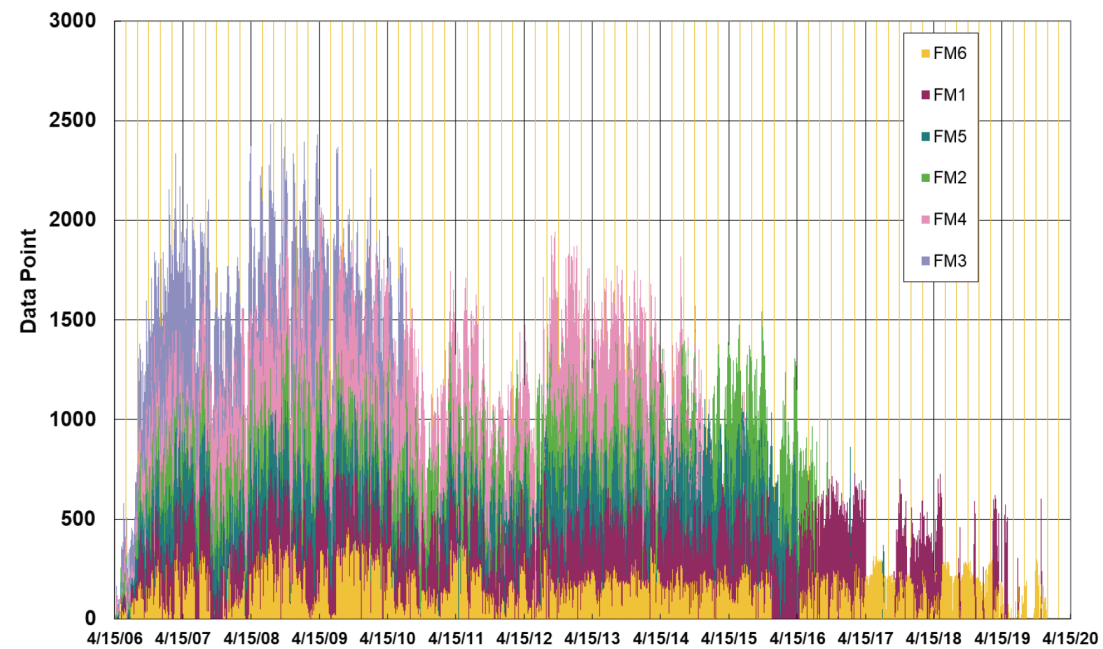

Fig. 2. FORMOSAT-3/COSMIC atmospheric occultation count per day from 2006 to 2020 . The constellation was capable of providing 1500 profiles every day in the first five years and several hundreds of data counts in its last five years. 
typhoon intensity forecast was also got improved while assimilating the FORMOSAT-3/COSMIC data into the NWP. Many studies also indicate that the assimilation with GNSS RO data improves the model initial condition over the northwestern Pacific region especially on the atmospheric moisture, and then has a better forecast on tropical cyclogenesis (Chen et al. 2020), typhoon (Chen et al. 2021b), and Mei-Yu front (e.g., Yang et al. 2014; Huang et al. 2016; Tu et al. 2017).

\subsection{FORMOSAT-3/COSMIC Data Gave Insights to Meteorology, Climate, and Space Sciences}

Using the data provided from FORMOSAT-3/COSMIC constellation, scientists in the fields of meteorology and space sciences have studied the disturbances triggered by earthquakes, tsunamis, volcano eruptions, solar eclipses, and magnetic storms. FORMOSAT-3/COSMIC was the first GPS-RO constellation mission in the world with uniform global coverage. With six satellites and an orbital period of 100 minutes, it took 16 days to provide a uniformly global coverage for all latitudes and all local times. This is effective to minimize diurnal variations of RO signals affecting climate changes and thus presents a significant advantage in climate monitoring.

\subsection{A Research Boom in the Areas of Space Weather and Ionospheric Research}

The FORMOSAT-3/COSMIC electron density profiles were employed to develop data assimilation systems for ionospheric weather monitoring, nowcasting, and forecasting, while FORMOSAT-3/COSMIC S4 data were used to examine the ionospheric scintillation effect on satellite positioning, navigation, and communication applications. Lee et al. (2012) and Hsu et al. (2014) used ensemble Kalman filter (EnKF) to assimilate EDFs of FORMOSAT-3/ COSMIC into Thermosphere Ionosphere Electrodynamics General Circulation Model (TIEGCM) for space weather forecasting. Lin et al. $(2015,2017)$ used Gauss-Markov Kalman Filter (GMKF) to assimilate FORMOSAT-3/COSMIC Total Electron Content (TEC) in ionospheric sphere into International Reference Ionosphere (IRI) model for space weather nowcasting. Liu et al. (2016) used S4 index profiles of FORMOSAT-3/COSMIC to estimate the worst case of GPS scintillations on the ground. Chen et al. (2017) used S4 index profiles of FORMOSAT-3/COSMIC to build an empirical model of L-band scintillation S4 index.

The 3D global electron density analysis from FORMOSAT-3/COSMIC provides an opportunity to observe the ionospheric plasma caves and ionospheric depletion bays, and improve the understanding of the equatorial ionization anomaly, mid-latitude trough, and high-latitude Weddell Sea/Yakutsk anomaly. Liu et al. (2010) used the EDF (Elec- tron Distribution Function) of FORMOSAT-3/COSMIC to observe the artificial plasma case that located underneath the equatorial ionization anomaly (EIA) crests along with three density enhancements in adjacent latitudes. Lin et al. (2010) and Chang et al. (2015) also used EDFs of FORMOSAT-3/COSMIC to study the activity of midlatitude summer nighttime anomaly and Weddell/Okhotsk Sea Anomaly (WSA) in ionosphere (Karia et al. 2019). Otherwise, Yeh et al. $(2012,2014)$ used the amplitude profiles to study the activity of ionospheric sporadic-E layer. Furthermore, the absolute TEC observation often used for plasmaspheric study. Chen (2009) and Cherniak et al. (2012) used absolute TEC data of FORMOSAT-3/COSMIC to study the plasmaspheric activity in solar minimum.

\section{FORMOSAT-7/COSMIC-2 MISSION STATUS}

Understanding the potential influence, NOAA and NSPO developed a plan collaboratively for a follow-on mission in the early 2008. The FORMOSAT-3/COSMIC was designed to achieve a five-year mission life. To ensure data continuity and to improve data quality and quantity with the state-of-the-art technology, NOAA and NSPO jointly started the planning of the next-generation - FORMOSAT-7/ COSMIC-2 mission in 2010.

Each FORMOSAT-7/COSMIC-2 satellite carries an advanced Tri-GNSS Radio-occultation System (TGRS) instrument. The TGRS, which is the mission payload developed by the experienced team of NASA's JPL, includes a next-generation high-gain beam-forming antenna to make the measurement penetrating to lower atmosphere through high signal-to-noise ratio (SNR) (higher than 2500 with a 1 $\mathrm{Hz}$ band). There are two science payloads onboard for each satellite: the Ion Velocity Meter (IVM) and the Radio Frequency Beacon (RFB) provided by United States Air Force. The IVM measures temperature, velocity, and density of ion. The RFB transmits signal from space, the corresponding ground receiver obtains the information of TEC and ionospheric scintillation.

There are nine worldwide ground stations support the mission; they route downlinked data to Taiwan and U.S. for data processing once the ground pass has been completed. This ground network makes the medium data latency of FORMOSAT-7/COSMIC- 2 data less than 45 minutes. In other words, the NWP and space weather forecast center can get more than $50 \%$ of data within 45 minutes since onboard sensors have collected it. The data are freely available from the US UCAR COSMIC website and Taiwan Analysis Center for COSMIC (TACC) website [i.e., CDAAC Website (https://cdaac-www.cosmic.ucar.edu/) and TACC Website (https://tacc.cwb.gov.tw/v2/en/index.html), respectively].

These six small satellites took a ride-share launch of the SpaceX Falcon Heavy rocket to a parking orbit of 720 $\mathrm{km}$ altitude and 24 degrees inclination angle in June 2019. 
Twenty months after launch, all six satellites have reached their final orbits as shown in Fig. 3. These six satellites now have been deployed to evenly spaced orbital planes as shown in Fig. 4. Please note that the orbital separation angle of FORMOSAT-3/COSMIC constellation is 30 degrees and that of FORMOSAT-7/COSMIC-2 is 60 degrees. Due to the design of orbit inclination angle and FORMOSAT-7/ COSMIC-2 is with GNSS (GPS and GLONASS) capability, the data density of FOMOISAT-7 is around 4 times of FORMOSAT-3/COSMIC near Taiwan. After six satellites reached mission orbit in February 2021, the spatial and temporal distribution of FORMOSAT-7/COSMIC-2 RO measurement become more uniform which is very beneficial for weather application.

Through several tunes and adjustments on the flight software and data processing system during calibration and validation phase, about $81 \%$ of sounding profiles of bending angles and refractivity, which collected from October 2019 to April 2020, can pass quality control. The FORMOSAT-7/COSMIC-2 data was validated and compared to other data sources. The evaluations have shown that the data already meet the defined users' performance requirements with accuracy, precision, and capability for superrefraction detection (Braun et al. 2019; Fong et al. 2019a, b; Schreiner et al. 2019, 2020; Shao et al. 2019; Weiss et al. 2019; Chen et al. 2021c) as shown in Table 1. After all six satellites have reached to the mission constellation, the percentage of sounding profiles meeting requirement increased to $89 \%$ based on the statistics in the time frame of 1 to 22 March 2021.

Following are the key highlights of the initial FORMOSAT-7/COSMIC-2 calibration/validation results by the joint Taiwan-U.S. team:

- The sounding can be successfully retrieved from both GPS and GLONASS RO measurements covering tropical and subtropical regions. Six FORMOSAT-7/COSMIC-2 satellites provide about 5000 profiles per day from about $45^{\circ} \mathrm{N}$ to $45^{\circ} \mathrm{S}$ latitude.

- TGRS mission payload is with high signal-to-noise (SNR) performance. The initial data of FORMOSAT-7/COSMIC-2 shows high accuracy and precision, deep penetration into the lower troposphere, and ability to detect ducting and super-refraction.

- With the increased data collection capability, the FORMOSAT-7/COSMIC-2 mission shows strong potential for improving the NWP models from mesoscale to synoptic scale. The early results from FORMOSAT-7/COSMIC-2 mission shows positive impact to improve operational forecast of severe weather events including typhoon/hurricane tracks and rainfall as well as Mei-Yu fronts to mitigate losses from disasters worldwide, but especially in the equatorial region.

- The FORMOSAT-7/COSMIC-2 mission is capable of supporting research for important atmospheric phenomena such as ozone depletion, planetary boundary layer, tropopause analysis, cloud/climate feedback, gravity waves, and atmospheric rivers. The high-SNR performance opens up an opportunity to study important physical processes over the tropics that will significantly benefit operational NWP forecasts and climate research.

- Large amount of measurements realized the nowcast and forecast of space weather, as well as provision of understanding of the coupling between ionosphere and atmosphere.

\section{FORMOSAT-7/COSMIC-2 DATA FIRST RESULTSFORMOSAT-7/COSMIC-2 FIRST RESULTS}

\subsection{The Application of FORMOSAT-7/COSMIC-2 to Atmosphere}

FORMOSAT-7/COSMIC-2 satellite is equipped with 12-elements GNSS phase array antenna, which is capable of observing the lower atmosphere. The histogram in Fig. 5 shows the distribution of penetrative depths of FORMOSAT-3/COSMIC and FORMOSAT-7/COSMIC-2 for 6 six months' worth of data.

The data used in this study was collected from October 2008 to March 2009 from FORMOSAT-3/COSMIC constellation and October 2019 to March 2020 from FORMOSAT-7/COSMIC- 2 constellation. The data amounts for FORMOSAT-7/COSMIC-2 are about three times than that for FORMOSAT-3/COSMIC. All the deepest penetration heights are stratified by a $500-\mathrm{m}$ interval till $6 \mathrm{~km}$, and the penetrative depth above $6 \mathrm{~km}$ is counted into the height of $5.5-6 \mathrm{~km}$ interval. The percentage of penetration below $1 \mathrm{~km}$ for FORMOSAT-7/COSMIC-2 is about $80 \%$ from October 2019 to March 2020, but only 40\% from October 2008 to March 2009 for FORMOSAT-3/COSMIC around tropical and sub-tropical region. After FORMOSAT-7/ COSMIC-2 satellites reached to their mission orbit in February 2021, the percentage of penetration increased slightly about $0.5 \%$. The detailed study on penetration of FORMOSAT-3/COSMIC can been found in Huang et al. (2009). The improved penetration capability of FORMOSAT-7/ COSMIC-2 is demonstrated from Fig. 6, the RO distribution on 3 February 2021. This the day which the sixth satellites were just maneuvered to final mission orbit altitude, there were $4815 \mathrm{RO}$ events were generated. The color indicates the deepest penetration height, most RO events could reach an altitude below $1 \mathrm{~km}$ over the ocean. It provides us very helpful information for studying the dynamics of water vapor and boundary layer over the ocean.

Even the retrieved atmospheric profiles show excellent penetration capability for FORMOSAT-7/COSMIC-2, but the quality might be still an issue for data assimilation. Due to multi-path occurred by the complex structure of water vapor, Liu et al. (2018) used the Local Spectral Width (LSW) 


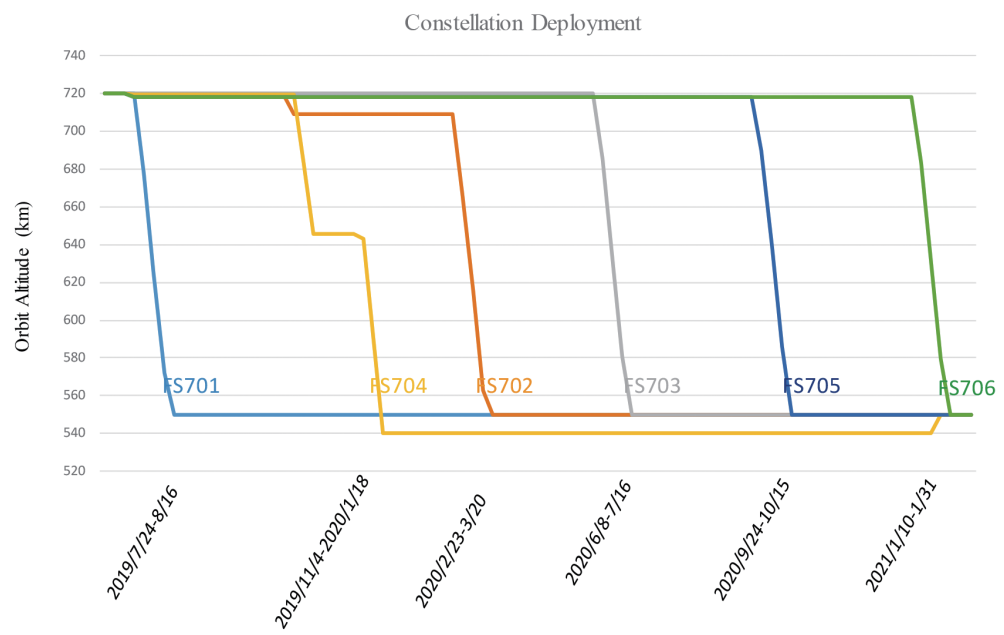

Fig. 3. FORMOSAT-7/COSMIC-2 Constellation Deployment. All six satellites were injected to a parking orbit of $720 \mathrm{~km}$. Through maneuvering satellite to $550 \mathrm{~km}$ one by one, the orbital planes were separated.

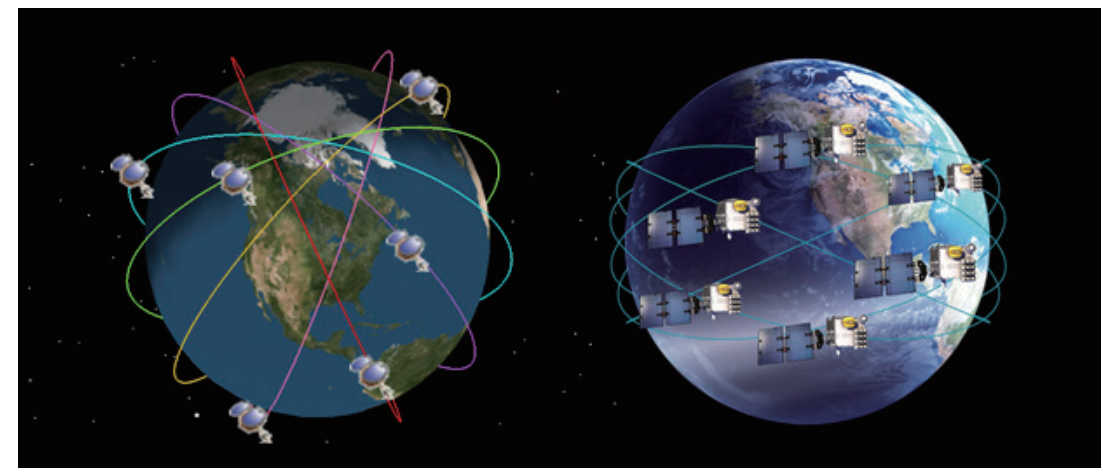

Fig. 4. FORMOSAT-3/COSMIC Constellation (left) and FORMOSAT-7/COSMIC-2 Constellation (right).

Table 1. FORMOSAT-7/COSMIC-2 RO Product Performance.

\begin{tabular}{c|cc}
\hline Description & Altitude Range [km] & Current Best Estimate \\
\hline Quality-Controlled Profile Count & & More than 4000 profiles per day \\
\hline Quality Control \% & & 81.0 \\
\hline & $5-5 \mathrm{~km}$ & 1555.9 \\
Bending angle profile measurement uncertainty $(\mu \mathrm{rad})$ & $10-20 \mathrm{~km}$ & 234.1 \\
& $20-30 \mathrm{~km}$ & 15.9 \\
& $30-60 \mathrm{~km}$ & 3.5 \\
& $0-5 \mathrm{~km}$ & 1.6 \\
\hline \multirow{3}{*}{ Refractivity profile measurement uncertainty $(\mathrm{N}$ units) } & $5-10 \mathrm{~km}$ & 3.1 \\
& $10-20 \mathrm{~km}$ & 0.5 \\
& $20-30 \mathrm{~km}$ & 0.076 \\
\hline Dry Temp profile measurement Uncertainty $(\mathrm{K})$ & $10-30 \mathrm{~km}$ & 0.028 \\
\hline Tropospheric duct height & $0.5-5 \mathrm{~km}$ & 0.68 \\
\hline \multirow{2}{*}{ TEC arcs (TECU) } & Absolute TEC & $50-100 \mathrm{~m}$ \\
\hline Scintillation & Relative TEC & 3 \\
\hline
\end{tabular}



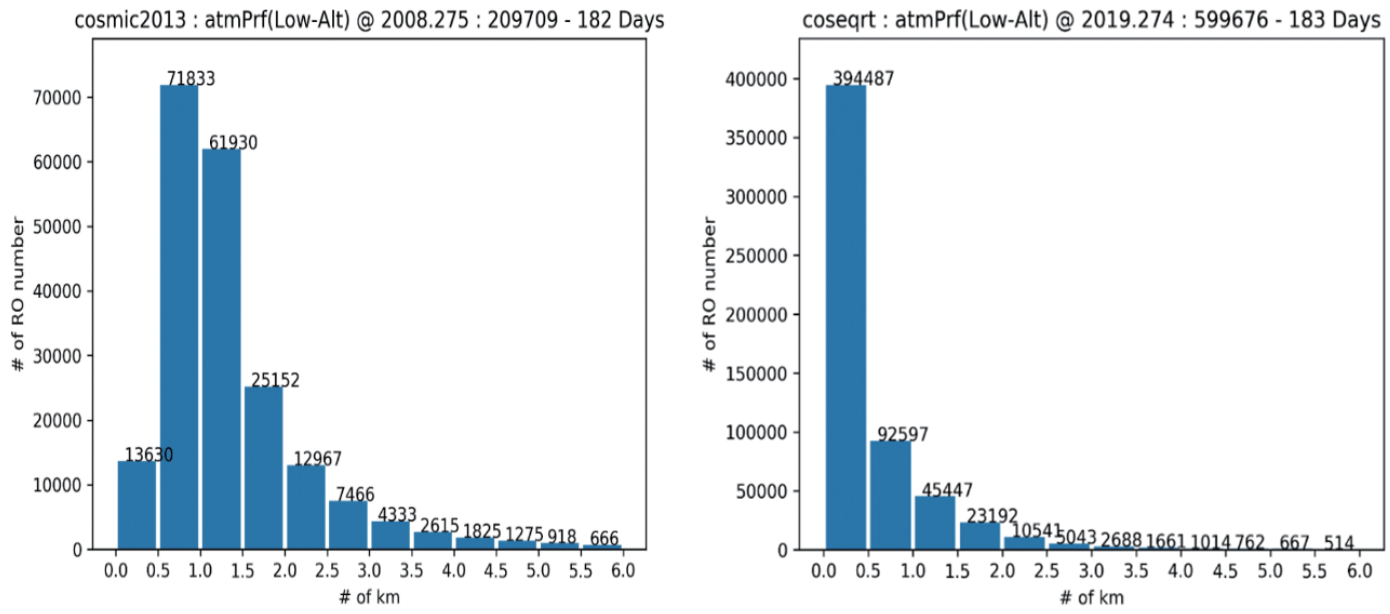

Fig. 5. Distribution of Penetrative Depths of FORMOSAT-3/COSMIC and FORMOSAT-7/COSMIC-2 (Chen et al. 2021c).

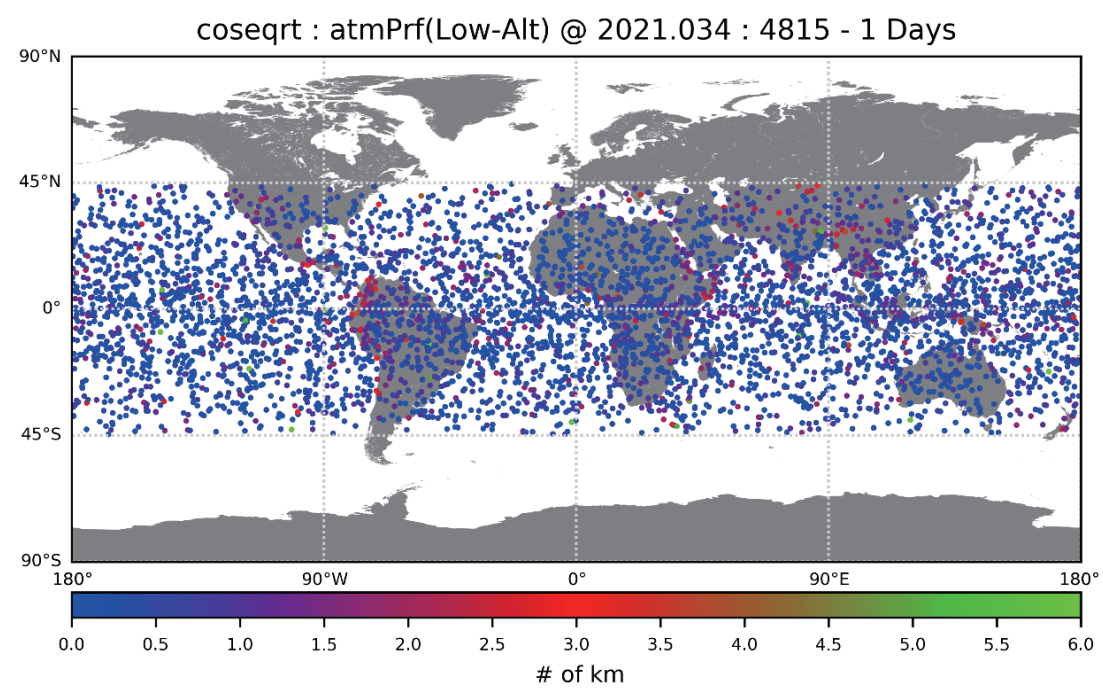

Fig. 6. The FORMOSAT-7/COSMIC-2 RO distribution on 2021.034, the color indicates the deepest penetration height of RO profiles.

to study the characterization of the uncertainty (random error) of retrieved bending angle and refractivity profiles in the tropical lower troposphere. They also took the LSW to examine the data quality for FORMOSAT-7/COSMIC-2 profiles (Liu et al. 2018; Chen and Huang 2020). As atmospheric temperature and humidity have a significant vertical gradient (such as the atmospheric boundary layer), the vertical refractive index gradient may exceed the critical refractive index. Therefore, super refraction will occur, resulting in a decrease in the data quality of the lower atmosphere data. In the following analysis, we will show a potential solution to filter out the degraded data.

Through studying the distribution of LSW values and dividing the signal azimuth into east-west and northsouth direction respectively as shown in Fig. 7. It seems the FORMOSAT-7/COSMIC-2 is more sensitive than FORMOSAT-3/COSMIC in the perturbation area at lower at- mosphere, but the trends of LSW are similar for boundary layer analysis.

Considering that the higher humidity near the equator and the moisture distribution easily gets uneven in the horizontal and vertical directions, that could reduce the quality of the RO profile and result in a larger LSW value for FORMOSAT-7/COSMIC-2 near the equator. The results suggest that users could implement a similar strategy to assimilate the FORMOSAT-7/COSMIC-2 data as the FORMOSAT-3/ COSMIC data, but must be carefully or may adapt other Quality Control (QC) strategy while using the profiles close to tropical region. For the applications to severe weather predictions, e.g., typhoon and frontal heavy rainfall, we realize that horizontal and vertical distributions of water vapor in these weather systems are very different. Therefore, we examined the vertical characteristics of the LSW within different weather systems to provide appropriate QC criteria 
for the assimilation of FORMOSAT-7/COSMIC-2 data.

By analyzing the vertical distribution of LSW probability between typhoon season and non-typhoon seasons depicted in Fig. 8, we found that the height of LSW increase to a higher altitude during typhoon-intensive period. The LSW in the typhoon active region is much smaller than the nonactive area. This phenomenon may be related to the strong updraft at the center of typhoon. When a large amount of water vapor is transmitted to the upper layer, the vertical distribution of water vapor become uniform, reducing the possibility of super refraction.

CWB's study from October 2019 to March 2020 showed the assimilation of FORMOSAT-7/COSMIC-2 data made statistically significant positive impact in tropics and neutral-to-positive impact in other areas (Lien et al. 2021). If RO observation below $4 \mathrm{~km}$ is used, the analyses showed there will be further improvement. CWB's analysis also showed assimilating FORMOSAT-7/COSMIC-2 data can improve prediction of typhoon initiation, structure, and track in addition to synoptic forecast. FORMOSAT-7/ COSMIC-2 data has been assimilated into operational NWP since 2020 (Lien et al. 2021). From early results also show positive impact with the FORMOSAT-7/COSMIC-2 data assimilation on tropical cyclone prediction (Chen et al. 2021d) and heavy rainfall forecast (Yang et al. 2020).

\subsection{Retrieval of Ionosphere Products}

Up to date, the released space weather products, including Absolute TEC, Electron Density Profiles (EDP) (provisional), and S4 index (provisional) derived from TGRS, can be download in Taiwan Analysis Center for COSMIC (TACC) and COSMIC Data Analysis and Archive Center (CDAAC).

In the other hand, NSPO worked with the teams of National Cheng Kung University (NCKU), National Central University (NCU), and Central Weather Bureau (CWB) to establish the Taiwan Radio Occultation Process System (TROPS) to provide the TGRS RO retrieval products. Currently, TROPS provides the EDF and S4 index at TACC website (https://tacc.cwb.gov.tw/v2/en/index.html).

To mitigate the artificial plasma structures introduced by the Abel inversion with assumption of spherical symmetry, improved Abel inversions were proposed by NCKU science team. The simplest way to resolve the artefacts is to provide the hemispheric asymmetric weighting to the Abel inversion. TECs from Global Ionosphere Map (GIM) (Hernandez-Pajares et al. 2000; Garcia-Fernandez et al. 2003; Pedatella et al. 2015), peak electron density of F-region ( $\mathrm{Tu}-$ lasi Ram et al. 2016), and in-situ electron densities along the occultation ray paths (Chou et al. 2017) are applied for calculation of the horizontal asymmetric weightings and they are termed as GIM-aided, NmF2-aided and Ne-aided Abel inversions, respectively. The performance of these aided
Abel inversions on the realistic FORMOSAT-7/COSMIC-2 data is given by Lin et al. (2020) showing promising improvement during both quiet and magnetic storm periods. The electron density profiles from the Ne-aided inversion are provided in the TROPS database at TACC website (https://tacc.cwb.gov.tw/v2/en/index.html).

NCU and NCKU have looked into the FORMOSAT-7/ COSMIC-2 data and products. Lin et al. (2020) used GaussMarkov Kalman Filter (GMKF) to assimilate FORMOSAT-7/COSMIC-2 TEC in ionosphere into International Reference Ionosphere (IRI) model for space weather nowcasting. Rajesh et al. (2021) also used FORMOSAT-7/COSMIC-2 TEC in ionosphere for assimilation to study a minor magnetic storm in deep solar minimum. Lin et al. (2020) reports the early results and validates FORMOSAT-7/COSMIC-2 space weather products. Rajesh et al. (2021) used ground GPS TEC for high latitude assimilation to compensate the data from FORMOSAT-7/COSMIC-2. Moreover, Chen et al. (2021a) used S4 index of FORMOSAT-7/COSMIC-2 to monitor the electric irregularities in near real time.

IVM provides the in-situ measurement of ion density, ion temperature, and ion velocity. The structures of ionospheric wavenumber-4 and plasma depletion bays at 700 and $500 \mathrm{~km}$ in altitude by using IVM data is shown in Liu et al. (2019). Chang et al. (2019) used the EDF from TGRS and ion density and drift from IVM of FORMOSAT-7/ COSMIC-2 to study the seismo-ionospheric precursors of the 14 November 2019 M7.1 Indonesia earthquake.

Because FORMOSAT-7/COSMIC-2 provides large amount of steady data with short latency, the scientists work diligently to continue the research from FORMOSAT-3/ COSMIC. And the data has been applied to space weather nowcast which website can be accessible from Space Weather Operations Office (SWOO) of CWB (https://swoo. cwb.gov.tw/V2/page/EN/index.html).

\section{CONCLUSIONS}

After fourteen years in orbit, the FORMOSAT-3/ COSMIC has demonstrated the value and importance of a RO satellite constellation in improving global weather prediction, climate monitoring, and ionospheric research. FORMOSAT-3/COSMIC data can be downloaded without registration since August 2020. The follow-on mission, FORMOSAT-7/COSMIC-2, with an advanced GNSS receiver and antenna design provides RO data with unprecedented quality that penetrates deep into the tropical lower troposphere. FORMOSAT-7/COSMIC-2 provides at least 4000 profiles for both neutral atmosphere and ionosphere each day, which covers the measurements over the ocean, within a latitude band of 45-degree. The data latency are specified as a median around 45 and 35 minutes for neutral atmospheric and ionospheric products, respectively. Early results have shown that FORMOSAT-7/COSMIC-2 can 
(a)

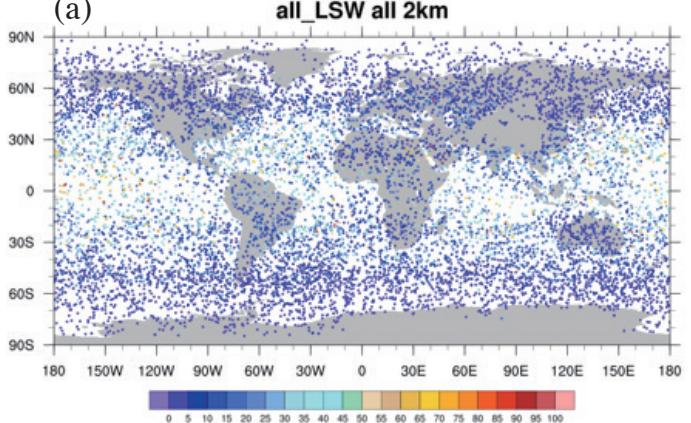

(b)
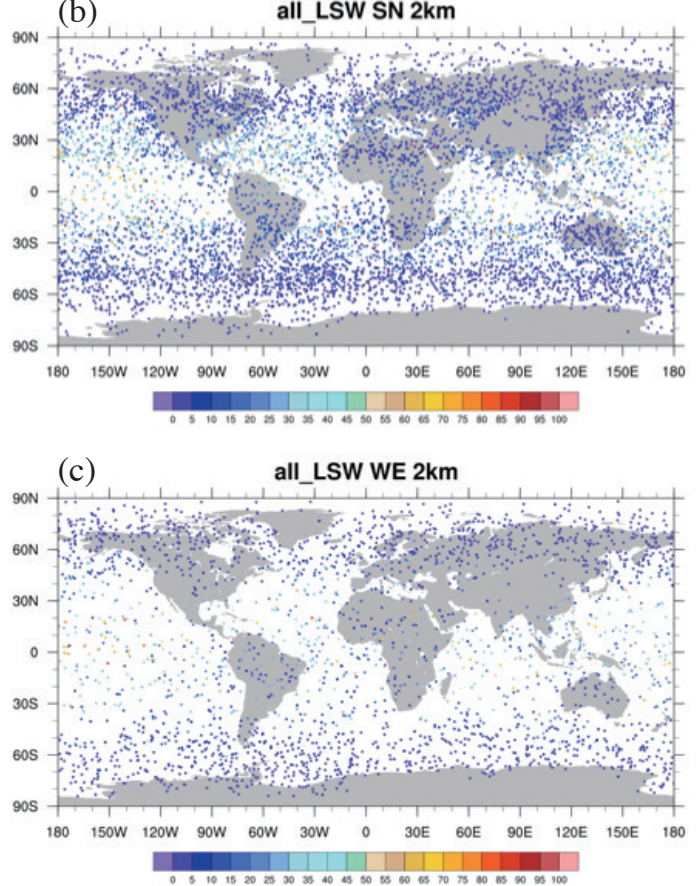

(d)

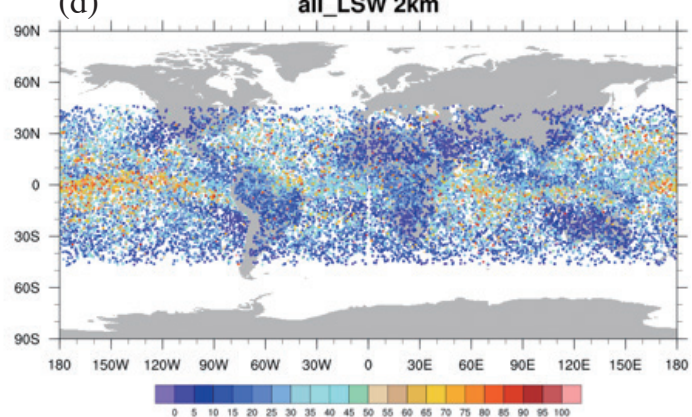

(e)
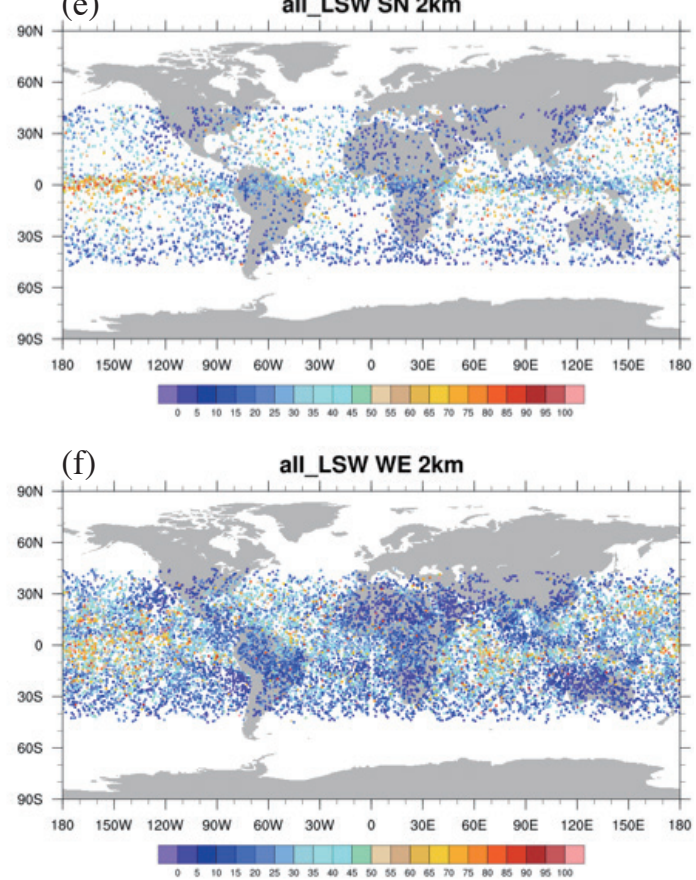

Fig. 7. Global distribution of LSW in the fall of 2019: (a) FORMOSAT-3/COSMIC, (b) FORMOSAT-3/COSMIC north-south direction, (c) FORMOSAT-3/COSMIC east-west direction, (d) FORMOSAT-7/COSMIC-2, (e) FORMOSAT-7/COSMIC-2 north-south direction, (f) FORMOSAT-7/COSMIC-2 east-west direction. The color scale represents the LSW value of $2 \mathrm{~km}$ high.

(a) The Probability Distribution(\%) of LSW (lat: -10-55)

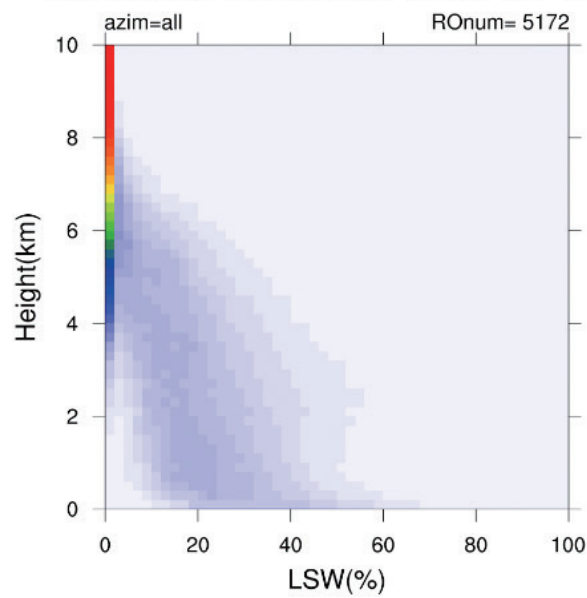

(b) The Probability Distribution(\%) of LSW (lat: -10-55)

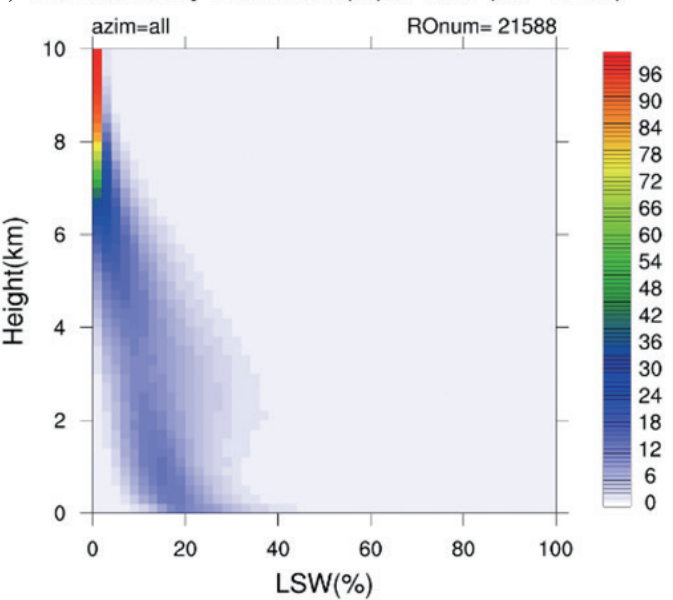

Fig. 8. LSW probability distribution in the summer of 2020: (a) During non-typhoon period in the Northwest Pacific region, (b) during the typhoonintensive period in the Northwest Pacific region. The color scale is the probability (\%) of LSW distribution at the same height. 
improve the prediction of tropical cyclogenesis and heavy rainfall events for neutral atmosphere, and monitor magnetic storm for ionosphere. The encouraging results of ionospheric products shed light on space weather nowcasting and forecasting which was never possible to expect. There is no question that FORMSOSAT-7 data will bring many scientific breakthroughs that benefit the global society.

In the past decades, the number of navigation systems deployed in space is increasing, including GPS, GLONASS, Galileo, Compass/BeiDou Navigation Satellite System, Quasi-Zenith Satellite System, and the Indian Regional Navigational Satellite System. These global navigation satellite systems offer a tremendous opportunity for the development of additional RO satellite constellation systems that can provide a large quantity of $\mathrm{RO}$ profiles for the atmospheric science community. ECMWF analysis showed even with 32000 - 128000 profiles per day, the improvement to weather forecast is still possible. FORMOSAT-3/ COSMIC and FORMOSAT-7/COSMIC-2 can contribute several thousands of measurements and have brought the RO constellation observation to a new era.

Acknowledgements The authors wish to express their gratitude for the contributions of the FORMOSAT-3/ COSMIC and FORMOSAT-7/COSMIC-2 program teams, the flight operation teams, the ground operation team, the anomaly resolution teams, the Taiwan science teams NCU and NCKU, and the cooperation of MOST (formerly NSC), CWB, NSF, UCAR, NCAR, JPL/NASA, NRL, USAF, NOAA, Orbital, and SSTL.

\section{REFERENCES}

Anthes, R. A., 2011: Exploring Earth's atmosphere with radio occultation: Contributions to weather, climate and space weather. Atmos. Meas. Tech., 4, 1077-1103, doi: 10.5194/amt-4-1077-2011. [Link]

Anthes, R. A., P. A. Bernhardt, Y. Chen, L. Cucurull, K. F. Dymond, D. Ector, S. B. Healy, S.-P. Ho, D. C. Hunt, Y.-H. Kuo, H. Liu, K. Manning, C. McCormick, T. K. Meehan, W. J. Randel, C. Rocken, W. S. Schreiner, S. V. Sokolovskiy, S. Syndergaard, D. C. Thompson, K. E. Trenberth, T.-K. Wee, N. L. Yen, and Z. Zeng, 2008: The COSMIC/FORMOSAT-3 Mission: Early Results. Bull. Amer. Meteorol. Soc., 89, 313-334, doi: 10.1175/BAMS-89-3-313. [Link]

Braun, J., D. Hunt, B. Schreiner, S. Sokolovskiy, I. Cherniak, Q. Wu, N. Pedatella, J. Weiss, P. Straus, T. Meehan, J. Tien, K. Groves, R. Caton, and Lt. M. Hauf, 2019: COSMIC-2 Early orbit space weather data assessment and validation activity. EUMETSAT ROM SAF - IROWG 2019, Konventum, Helsigor (Elsinore), Denmark. Available at https://www.romsaf. org/romsaf-irowg-2019/en/abstract/94.
Cardinali, C. and. S. Healy, 2014: Impact of GPS radio occultation measurements in the ECMWF system using adjoint-based diagnostics. Q.J.R. Meteorol.Soc., 140, 2315-2320, doi: 10.1002/qj.2300. [Link]

Chang, F. Y., J. Y. Liu, L. C. Chang, C. H. Lin, and C. H. Chen, 2015: Three-dimensional electron density along the WSA and MSNA latitudes probed by FORMOSAT-3/COSMIC. Earth Planets Space, 67, doi: 10.1186/s40623-015-0326-8. [Link]

Chang, F.-Y., C.-Y. Lin, I.-T. Lee, Y.-I. Chen, and C.-K. Chao, 2019: An observing system simulation experiment for FORMOSAT-7/COSMIC-2 detecting seismo-ionospheric precursors. Abstract \#NH52B-02, American Geophysical Union, Fall Meeting 2019, San Francisco, USA.

Chen, C.-Y., 2009: The observation of plasmaspheric electron content by FORMOSAT-3/COSMIC. Master Thesis, Graduate Institude of Space Science, National Central University, Taoyuan City, Taiwan.

Chen, S.-P., D. Bilitza, J.-Y. Liu, R. Caton, L. C. Chang, and W.-H. Yeh, 2017: An empirical model of L-band scintillation S4 index constructed by using FORMOSAT-3/COSMIC data. Adv. Space Res., 60, 10151028, doi: 10.1016/j.asr.2017.05.031. [Link]

Chen, S.-P., C. C. H. Lin, P. K. Rajesh, J.-Y. Liu, R. Eastes, M.-Y. Chou, and J.-M. Choi, 2021a: Near real-time global plasma irregularity monitoring by FORMOSAT-7/COSMIC-2. J. Geophys. Res., 126, e2020JA028339, doi: 10.1029/2020JA028339. [Link]

Chen, S.-Y., Y.-H. Kuo, and C.-Y. Huang, 2020: The Impact of GPS RO Data on the Prediction of Tropical Cyclogenesis Using a Nonlocal Observation Operator: An Initial Assessment. Mon. Weather Rev., 148, 27012717, doi: 10.1175/MWR-D-19-0286.1. [Link]

Chen, S.-Y., C.-Y. Liu, C.-Y. Huang, S.-C. Hsu, H.-W. Li, P.-H. Lin, J.-P. Cheng, and C.-Y. Huang, 2021b: An Analysis Study of FORMOSAT-7/COSMIC-2 Radio Occultation Data in the Troposphere. Remote Sens.,13, 717, doi: 10.3390/rs13040717. [Link]

Chen, S.-Y., C.-P. Shih, C.-Y. Huang, and W.-H. Teng, 2021c: An Impact Study of GNSS RO Data on the Prediction of Typhoon Nepartak (2016) Using a Multiresolution Global Model with 3D-Hybrid Data Assimilation. Weather Forecast., 36, 957-977, doi: 10.1175/ WAF-D-20-0175.1. [Link]

Chen, S.-Y., C.-Y. Huang, G.-Y. Lien, H.-H. Ho, H.-W. Li, C.-C. Lin, J.-Y. Huang, and Y.-H. Chen, 2021d: The Validation and Application of FORMOSAT-7/COSMIC-2 Radio Occultation Data from Taiwan Team. $8^{\text {th }}$ International Radio Occultation Working Group Meeting - IROWG-8. Available at https://cpaess.ucar.edu/ sites/default/files/meetings/2020/presentations/chenpresentation.pdf.

Chen, Y.-H. and C.-Y. Huang, 2020: Analysis of LSW 
Characteristics at Planetary Boundary Layer Height. $5^{\text {th }}$ International Conference on GPS radio Occultation in 2020. Available at https://w3.nspo.narl.org.tw/ICGPSRO2020/download/PDF/AB018.pdf.

Cherniak, I. V., I. E. Zakharenkova, A. Krankowski, and I. I. Shagimuratov, 2012: Plasmaspheric electron content derived from GPS TEC and FORMOSAT-3/COSMIC measurements: Solar minimum condition. Adv. Space Res., 50, 427-440, doi: 10.1016/j.asr.2012.04.002. [Link]

Chien, F.-C., J.-S. Hong, and Y.-H. Kuo, 2016: Estimation of marine boundary layer heights over the western North Pacific using GPS radio occultation profiles. SOLA, 12, 302-306, doi: 10.2151/sola.2016-059. [Link]

Chien, F.-C., J.-S. Hong, and Y.-H. Kuo, 2019: The marine boundary layer height over the western North Pacific based on GPS radio occultation, island soundings, and numerical models. Sensors, 19, 155, doi: 10.3390/ s19010155. [Link]

Chou, M. Y., C. C. H. Lin, H. F. Tsai, and C. Y. Lin, 2017: Ionospheric electron density inversion for Global Navigation Satellite Systems radio occultation using aided Abel inversions. J. Geophys. Res., 122, 1386-1399, doi: 10.1002/2016JA023027. [Link]

Chu, C.-H. V., S.-K. Yang, C.-J. Fong, N. Yen, T.-Y. Liu, W.-J. Chen, D. Hawes, Y.-A. Liou, and B. Kuo, 2007: The most accurate and stable space-borne thermometers - FORMOSAT-3/COSMIC constellation. 2007 Small Satellite Conference, SSC07-VII-1. Available at https://digitalcommons.usu.edu/cgi/viewcontent.cgi?a rticle $=1476 \&$ context $=$ smallsat .

Digregorio, B. E., 2006: Roundabout way of profiling Earth's atmosphere. IEEE Spectr., 43, 22-23, doi: 10.1109/mspec.2006.1611754. [Link]

Fong, C.-J., C.-H. Chu, C.-L. Lin, and A. d. S. Curiel, 2019a: Toward the Most Accurate Thermometer in Space: FORMOSAT-7/COSMIC-2 Constellation. IEEE Aerosp. Electron. Syst. Mag., 34, 12-20, doi: 10.1109/MAES.2019.2924133. [Link]

Fong, C.-J., V. Chu, and C.-C. Lin, 2019b: From FORMOSAT-3/COSMIC to FORMOSAT-7/COSMIC-2 mission: A new era of operational GNSS radio occultation constellation observing system. EUMETSAT ROM SAF - IROWG 2019, Konventum, Helsigor (Elsinore), Denmark. Available at https://www.romsaf. org/romsaf-irowg-2019/en/abstract/5.

Garcia-Fernandez, M., M. Hernandez-Pajares, M. Juan, and J. Sanz, 2003: Improvement of ionospheric electron density estimation with GPSMET occultations using Abel inversion and VTEC information. J. Geophys. Res., 108, 1338, doi: 10.1029/2003JA009952. [Link]

Guo, P., Y.-H. Kuo, S. V. Sokolovskiy, and D. H. Lenschow, 2011: Estimating Atmospheric Boundary Layer Depth Using COSMIC Radio Occultation Data. J. Atmos. Sci.,
68, 1703-1713, doi: 10.1175/2011JAS3612.1. [Link]

Hernandez-Pajares, M., J. M. Juan, and J. Sanz, 2000: Improving the Abel inversion by adding ground GPS data to LEO radio occultations in ionospheric sounding. Geophys. Res. Lett., 27, 2473-2476, doi: 10.1029/2000GL000032. [Link]

Ho, S.-P., R. A. Anthes, C. O. Ao, S. Healy, A. Horanyi, D. Hunt, A. J. Mannucci, N. Pedatella, W. J. Randel, A. Simmons, A. Steiner, F. Xie, X. Yue, and Z. Zeng, 2020: The COSMIC/FORMOSAT-3 Radio Occultation Mission after 12 Years: Accomplishments, Remaining Challenges, and Potential Impacts of COSMIC-2. Bull. Amer. Meteorol. Soc., 101, E1107E1136, doi: 10.1175/BAMS-D-18-0290.1. [Link]

Hsu, C.-T., T. Matsuo, W. Wang, and J.-Y. Liu, 2014: Effects of inferring unobserved thermospheric and ionospheric state variables by using an Ensemble Kalman Filter on global ionospheric specification and forecasting. J. Geophys. Res., 119, 9256-9267, doi: 10.1002/2014ja020390. [Link]

Huang, C.-Y., C.-Z.Cheng, P.-H.Lin, C.-J. Fong, J. Wickert, and C.-C. Hsiao, 2009: Radio Occultation Retrieval of Atmospheric Profiles from the FORMOSAT-3/COSMIC Mission: Early Results. Terr. Atmos. Ocean. Sci., 20, 21-34, doi: 10.3319/TAO.2008.04.24.01(F3C). [Link]

Huang, C.-Y., S.-Y. Chen, S. K. A. V. P. Rao Anisetty, S.C. Yang, and L.-F. Hsiao, 2016: An Impact Study of GPS Radio Occultation Observations on Frontal Rainfall Prediction with a Local Bending Angle Operator. Weather Forecast., 31, 129-150, doi: 10.1175/WAFD-15-0085.1. [Link]

IPCC, 2013: Summary for Policymakers. In: Stocker, T. F., D. Qin, G.-K. Plattner, M. Tignor, S. K. Allen, J. Boschung, A. Nauels, Y. Xia, V. Bex, and P. M. Midgley (Eds.), Climate Change 2013: The Physical Science Basis, Contribution of Working Group I to the Fifth Assessment Report of the Intergovernmental Panel on Climate Change, Cambridge University Press, Cambridge, United Kingdom and New York, NY, USA.

Karia, S. P., J. H. Kim, A. O. Afolayan, and T. I. Lin, 2019: A study on Nighttime Winter Anomaly (NWA) and other related Mid-latitude Summer Nighttime Anomaly (MSNA) in the light of International Reference Ionosphere (IRI) - Model. Adv. Space Res., 63, 19491960, doi: 10.1016/j.asr.2018.11.021. [Link]

Kurino, T., 2016: GNSS Radio-occultation in the WMO integrated global observing system. Intern. Radio Occultation Working Group, Estes Park.

Lee, I. T., T. Matsuo, A. D. Richmond, J. Y. Liu, W. Wang, C. H. Lin, J. L. Anderson, and M. Q. Chen, 2012: Assimilation of FORMOSAT-3/COSMIC electron density profiles into a coupled thermosphere/ionosphere model using ensemble Kalman filtering. J. Geophys. 
Res., 117, A10318, doi: 10.1029/2012ja017700. [Link] Lien, G.-Y., C.-H. Lin, Z.-M. Huang, W.-H. Teng, J.-H. Chen, C.-C. Lin, H.-H. Ho, J.-Y. Huang, J.-S. Hong, C.-P. Cheng, and C.-Y. Huang, 2021: Assimilation Impact of Early FORMOSAT-7/COSMIC-2 GNSS Radio Occultation Data with Taiwan's CWB Global Forecast System. Mon. Weather Rev., 149, 2171-2191, doi: 10.1175/MWR-D-20-0267.1. [Link]

Lin, C. H., C. H. Liu, J. Y. Liu, C. H. Chen, A. G. Burns, and W. Wang, 2010: Midlatitude summer nighttime anomaly of the ionospheric electron density observed by FORMOSAT-3/COSMIC. J. Geophys. Res., 115, A03308, doi: 10.1029/2009ja014084. [Link]

Lin, C. Y., T. Matsuo, J. Y. Liu, C. H. Lin, H. F. Tsai, and E. A. Araujo-Pradere, 2015: Ionospheric assimilation of radio occultation and ground-based GPS data using non-stationary background model error covariance. Atmos. Meas. Tech., 8, 171-182, doi: 10.5194/amt-8171-2015. [Link]

Lin, C. Y., T. Matsuo, J. Y. Liu, C. H. Lin, J. D. Huba, H. F. Tsai, and C. Y.Chen, 2017: Data assimilation of groundbased GPS and radio occultation total electron content for global ionospheric specification. J. Geophys. Res., 122, 10876-10886, doi: 10.1002/2017ja024185. [Link]

Lin, C.-Y., C. C.-H. Lin, J.-Y. Liu, P. K. Rajesh, T. Matsuo, M.-Y. Chou, H.-F. Tsai, and W.-H. Yeh, 2020: The Early Results and Validation of FORMOSAT-7/COSMIC-2 Space Weather Products: Global Ionospheric Specification and Ne-Aided Abel Electron Density Profile. J. Geophys. Res., 125, e2020JA028028, doi: 10.1029/2020ja028028. [Link]

Liou, Y.-A., A. G. Pavelyev, S.-F. Liu, A. A. Pavelyev, N. Yen, C.-Y. Huang, and C.-J. Fong, 2007: FORMOSAT-3/COSMIC GPS Radio Occultation Mission: Preliminary Results. IEEE Trans. Geosci. Remote Sensing, 45, 3813-3826, doi: 10.1109/TGRS.2007.903365. [Link]

Liu, H., Y.-H. Kuo, S. Sokolovskiy, X. Zou, Z. Zeng, L.-F. Hsiao, and B. C. Ruston, 2018: A Quality Control Procedure Based on Bending Angle Measurement Uncertainty for Radio Occultation Data Assimilation in the Tropical Lower Troposphere. J. Atmos. Ocean. Technol., 35, 2117-2131, doi: 10.1175/jtech-d-17-0224.1. [Link]

Liu, J. Y., C. Y. Lin, C. H. Lin, H. F. Tsai, S. C. Solomon, Y. Y. Sun, I. T. Lee, W. S. Schreiner, and Y. H. Kuo, 2010: Artificial plasma cave in the low-latitude ionosphere results from the radio occultation inversion of the FORMOSAT-3/COSMIC. J. Geophys. Res., 115, A07319, doi: 10.1029/2009ja015079. [Link]

Liu, J. Y., S. P. Chen, W. H. Yeh, H. F. Tsai, and P. K. Rajesh, 2016: Worst-case GPS scintillations on the ground estimated from radio occultation observations of FORMOSAT-3/COSMIC during 2007-2014. Surv.
Geophys., 37, 791-809, doi: 10.1007/s10712-0159355-X. [Link]

Liu, T. J.-Y., T.-Y.Liu, C.-Y.Lin, F.-Y. Chang, C.-K. Chao, L. C. Chang, W.-H. Yeh, S.-P. Chen, C. C.-H. Lin, C.H. Chu, K.-L. Chen, I.-T. Lee, and C.-P. Cheng, 2019: Early results of ionospheric weather observations of FORMOSAT-7/COSMIC-2. Abstract \#G21B-0739, American Geophysical Union, Fall Meeting 2019, San Francisco, USA.

Mannucci, A. J., S. Healy, and U. Foelsche, 2018: Report of IROWG activities: Outcome and recommendations from the IROWG-6. CGMS-46 IROWG-WP-01, Meeting of the Coordination Group for Meteorological Satellites.

NOAA National Centers for Environmental Information (NOAA NCEI), 2020a: State of the Climate: Global Climate Report for Annual 2019. (Retrieved on 19 January 19 2020.) Available at https://www.ncdc.noaa. gov/sotc/global/201913.

NOAA National Centers for Environmental Information (NOAA NCEI), 2020b: U.S. Billion-Dollar Weather and Climate Disasters. Available at https://www.ncdc. noaa.gov/billions/.

Pedatella, N. M., X. Yue, and W. S. Schreiner, 2015: An improved inversion for FORMOSAT-3/COSMIC ionosphere electron density profiles. J. Geophys. Res., 120, 8942-8953, doi: 10.1002/2015JA021704. [Link]

Pica, J. A., 2016: Observations that support a weather-ready nation: The Importance of COSMIC-2 FORMOSAT-7. 3rd ICGPSRO, Taipei, Taiwan.

Rajesh, P. K., C. H. Lin, C. Y. Lin, C. H. Chen, J. Y. Liu, T. Matsuo, S. P. Chen, W. H. Yeh, and C. Y. Huang, 2021: Extreme positive ionosphere storm triggered by a minor magnetic storm in deep solar minimum revealed by FORMOSAT-7/COSMIC- 2 and GNSS Observations. J. Geophys. Res., 126, e2020JA028261, doi: 10.1029/2020JA028261. [Link]

Schreiner, B., S. Sokolovskiy, J. Weiss, J. Braun, R. Anthes, Y.-H. B. Kuo, D. Hunt, Z. Zeng, T.-K. Wee, T. VanHove, J. Sjoberg, and H. Huelsing, 2019: Performance assessment and requirement verification of COSMIC-2 neutral atmospheric radio occultation data. EUMETSAT ROM SAF - IROWG 2019, Konventum, Helsigor (Elsinore), Denmark. Available at https://www. romsaf.org/romsaf-irowg-2019/en/abstract/77.

Schreiner, W. S., 2020: Final Report for the NSPO-UCAR AIT-TECRO Agreement Implementing Arrangement \#5, UCAR COSMIC Program.

Schreiner, W. S., J. P. Weiss, R. A. Anthes, J. Braun, V. Chu, J. Fong, D. Hunt, Y.-H. Kuo, T. Meehan, W. Serafino, J. Sjoberg, S. Sokolovskiy, E. Talaat, T. K. Wee, and Z. Zeng, 2020: COSMIC-2 radio occultation constellation: First results. Geophys. Res. Lett., 47, e2019GL086841, doi: 10.1029/2019GL086841. [Link] 
Shao, H., H. Zhang, S. Dutta, F. Vandenberghe, Z.-M. Huang, J. G. Yoe, A. Collard, D. Kleist, and T. Auligné, 2019: GNSS-RO data assimilation advancement and implementation at JCSDA and NCEP. EUMETSAT ROM SAF - IROWG 2019, Konventum, Helsigor (Elsinore), Denmark. Available at https://www. romsaf.org/romsaf-irowg-2019/en/abstract/22.

Sokolovskiy, S., 2004: Open Loop Tracking and Inverting GPS Radio Occultation Signals: Simulation Study. In: Kirchengast, G., U. Foelsche, and A. K. Steiner (Eds.), Occultations for Probing Atmosphere and Climate, Springer, Berlin, Heidelberg, 39-51, doi: 10.1007/9783-662-09041-1_4. [Link]

Tu, C.-C., Y.-L. Chen, S.-Y. Chen, Y.-H. Kuo, and P.-L. Lin, 2017: Impacts of including rain-evaporative cooling in the initial conditions on the prediction of a coastal heavy rainfall event during TiMREX. Mon. Weather Rev., 145, 253-277, doi: 10.1175/mwr-d-16-0224.1. [Link]

Tulasi Ram, S., S.-Y.Su, L.-C. Tsai, and C. H. Liu, 2016: A self-contained GIM-aided Abel retrieval method to improve GNSS-radio occultation retrieved electron density profiles. GPS Solut., 20, 825-836, doi: 10.1007/ s10291-015-0491-z. [Link]

Wang, K.-Y., 2017: Climate change detection with the FORMOSAT-3/COSMIC GPS RO satellite. J. Aeronaut. Aerospace Eng., 6, 97, doi: 10.4172/2168-9792C1-017. [Link]

Weiss, J. P., 2019: FORMOSAT-7/COSMIC-2 Neutral Atmosphere Provisional Data Release 1, FORMOSAT-7/ COSMIC-2 Program.

Weiss, J. P., 2020: FORMOSAT-7/COSMIC-2 Neutral Atmosphere Initial Operating Capability Data Release,
FORMOSAT-7/COSMIC-2 Program.

Weiss, J. P., W. Xia-Serafino, and the COSMIC-2 Team, 2019: FORMOSAT-7/COSMIC-2 mission status and initial results. EUMETSAT ROM SAF - IROWG 2019, Konventum, Helsigor (Elsinore), Denmark. Available at https://www.romsaf.org/romsaf-irowg-2019/en/abstract/24.

Yang, S.-C., S.-H. Chen, S.-Y. Chen, C.-Y. Huang, and C.-S. Chen, 2014: Evaluating the impact of the COSMIC RO bending angle data on predicting the heavy precipitation episode on 16 June 2008 during SoWMEX-IOP8. Mon. Weather Rev., 142, 4139-4163, doi: 10.1175/mwr-d-13-00275.1. [Link]

Yang, S.-C., C.-C. Chang, and S.-H. Chen, 2020: The Impact of Formosa7/COSMIC-II Radio Occultation Data on Heavy Rainfall Prediction. $5^{\text {th }}$ International Conference on GPS radio Occultation in 2020. Availableat https://w3.nspo.narl.org.tw/ICGPSRO2020/download/ PDF/AB063.pdf.

Yeh, W.-H., C.-Y. Huang, T.-Y. Hsiao, T.-C. Chiu, C.-H. Lin, and Y.-A. Liou, 2012: Amplitude morphology of GPS radio occultation data for sporadic-Elayers.J.Geophys.Res., 117, A11304, doi: 10.1029/2012JA017875. [Link]

Yeh, W.-H., J.-Y. Liu, C.-Y. Huang, and S.-P. Chen, 2014: Explanation of the sporadic- $E$ layer formation by comparing FORMOSAT-3/COSMIC data with meteor and wind shear information. J. Geophys. Res., 119, 45684579, doi: 10.1002/2013JD020798. [Link]

Yen, N. L. and C.-J. Fong, 2009: FORMOSAT-3 Evaluation Report and Follow-on Mission Plan. NSPORPT-0047_0101, National Space Organization, Hsinchu, Taiwan. 